ORIGINAL ARTICLE

\title{
Safety and Feasibility of Dual-task Rehabilitation Program for Body Trunk Balance Using Virtual Reality and Three-dimensional Tracking Technologies
}

\author{
Masahiko Hara, MD, PhD ${ }^{\text {a, b }}$ Tetsuhisa Kitamura, MD, MSc, DrPH ${ }^{c}$ Yuichiro Murakawa, OT, MHSc ${ }^{d}$ \\ Kyosuke Shimba ${ }^{b}$ Shimpei Yamaguchi ${ }^{b}$ and Masatake Tamaki, MCMS ${ }^{b}$
}

\begin{abstract}
Objective: The ability to walk is one of the most important basic functional activities of daily living, and the number of patients with walking disability who need rehabilitation is increasing worldwide. The purpose of this first-in-man study was to evaluate the safety and feasibility of an off-label, tailor-made, dual-task rehabilitation program for body trunk balance using the mediVR01 system (mediVR, Inc. Osaka, Japan), which incorporates virtual reality (VR) and three-dimensional tracking technologies. Methods: We prospectively enrolled 31 healthy volunteers to take part in the trial (Trial Registration UMIN000029659). After an assessment of body trunk balance, a tailor-made, dual-task, rehabilitation training program lasting 10-15 min was provided. The primary endpoint was the postprocedural number of simulator sickness questionnaire (SSQ) symptoms. The secondary endpoints were adverse events and satisfaction with the program. Results: The median age of participants was 68 years, with $67.7 \%$ being elderly $(>65$ years) and $54.8 \%$ being male. The number of SSQ symptoms immediately after the rehabilitation programs significantly increased from 0 (interquartile range $0-0)$ to $0(0-1.5)(\mathrm{P}=0.009)$, with a significant difference between the young and elderly participants (P-interaction $<0.001$ ). The most frequent symptom was sweating $(22.6 \%)$, followed by fatigue $(19.4 \%)$. All participants successfully completed the rehabilitation programs without significant adverse events such as fall or injuries. Moreover, all participants considered the VR rehabilitation programs to be enjoyable, and $93.5 \%$ of participants reported a sense of achievement. Group attendance was associated with higher levels of satisfaction $(\mathrm{P}=0.049)$. Conclusion: The tailor-made, dual-task rehabilitation training programs for body trunk balance using VR and three-dimensional tracking technologies were safe and feasible even for elderly participants.
\end{abstract}

Key words: body trunk balance; dual-task rehabilitation; first-in-man; mediVR01; virtual reality

\section{INTRODUCTION}

The ability to walk is one of the most important basic functional activities of daily living (ADLs). This ability can be impaired by various conditions, including cerebrovascular diseases such as stroke, neurodegenerative diseases such as Parkinson's disease and dementia, sarcopenia, and frailty; in geriatric patients, even hospitalization can have an adverse effect. ${ }^{1-6)}$ As the world's population ages, the number of patients with walking disability increases. In many countries, this may result in a demand-supply mismatch in the clinical setting caused by inadequate human resources, such as insufficient numbers of physical therapists or caregivers, or problems with the costs of home and outpatient healthcare. $^{2,7-9)}$

Received: July 26, 2018, Accepted: October 15, 2018, Published online: October 24, 2018

${ }^{a}$ Center for Community-based Healthcare Research and Education, Shimane University, Izumo, Japan

b Department of Medical Device Development, mediVR, Inc., Osaka, Japan

${ }^{\mathrm{c}}$ Division of Environmental Medicine and Population Sciences, Department of Social and Environmental Medicine, Osaka University Graduate School of Medicine, Suita, Japan

${ }^{\mathrm{d}}$ Division of Stroke Rehabilitation, National Cerebral and Cardiovascular Center Hospital, Suita, Japan

Correspondence: Masahiko Hara, MD, PhD, Center for Community-based Healthcare Research and Education, Shimane University,

223-8 Enya-cho, Izumo, Shimane 693-8501, Japan, E-mail: hara@japanscr.org

Copyright (C) 2018 The Japanese Association of Rehabilitation Medicine 
To maintain or regain walking ability so that ADLs can be performed safely, exercise rehabilitation focusing on body trunk balance and muscle strengthening of the lower extremities is recommended by international guidelines, such as those for stroke survivors. ${ }^{10)}$ Whereas, muscle strengthening can be provided using a fixed program, it is difficult to provide tailor-made rehabilitation programs for body trunk balance without an experienced physical therapist because real-time quantitative instructions and tools for concomitant assessment are lacking. ${ }^{8,11)}$ Moreover, exercise rehabilitation programs should ideally use technology also to stimulate the cognitive function to help prevent falls (so-called "dual-task" training) and should include an element of entertainment to discourage discontinuity or withdrawal from the rehabilitation intervention. ${ }^{12-17)}$

To meet these ideal criteria for body trunk balance training, we developed a tailor-made, dual-task, rehabilitation training program using virtual reality (VR) and threedimensional tracking technologies to provide patients with an exercise rehabilitation program with an element of gamification. This study aimed to evaluate the safety and feasibility of this approach by focusing on the incidence of VR sickness in subjects using a new off-label VR rehabilitation training program for body trunk balance, namely the mediVR01.

\section{METHODS}

\section{Participant Involvement}

This study was a prespecified phase I clinical study that aimed to evaluate the safety and feasibility of an off-label medical device, the mediVR01 (mediVR, Inc., Osaka, Japan). The mediVR01 provides patients with a standardized, tailor-made, dual-task exercise rehabilitation program for body trunk balance using VR and three-dimensional tracking technologies (HTC Vive ${ }^{\circledR}$, HTC Corporation, New Taipei City, Taiwan). All subjects were healthy adult volunteers, and the exclusion criteria were a medical history of (1) vertigo, dizziness, Meniere's disease, or other semicircular canal or inner ear problems; (2) untreated poor vision; (3) epilepsy; (4) postural dizziness or hypotension; (5) participation in another clinical study within 3 months; (6) and psychiatric disorder or loss of the ability to understand; (7) further, volunteers considered to be inappropriate candidates based on the attending physician's discretion were also excluded. Of 33 healthy volunteers enrolled between November 1 and December 28, 2017, one volunteer disagreed with our privacy policy and another candidate with Meniere's disease met one of the exclusion criteria of the present study. Finally
31 participants completed the study and enrolled in the final analysis. The study protocol complied with the standards of the Declaration of Helsinki and was approved by the Ethics Committee of the Japan Society of Clinical Research (approval number 201706). Written informed consent was obtained from all study participants, and participants were informed that the study results would be disseminated as a journal article. This study was registered at the University Hospital Medical Information Network Clinical Trials Registry (UMIN000029659) and meets the criteria of the International Committee of Medical Journal Editors (ICMJE).

\section{Study Protocol}

As shown in Fig. 1A, participants sit on an upright chair, wear a head-mounted display (HMD) and a central tracker located near the supraclavicular fossa, and grasp two handheld controllers. The VR system locates participants in a motion-tracked three-dimensional space called "room scale" of the HTC Vive set. HTC Vive can provide users with graphics at $>90$ frames/s (fps) with an approximately $110^{\circ}$ viewing angle and includes accurate three-dimensional tracking technology.

For calibration, we evaluated conventional reaching distances (colored blue in Fig. 1A and 1B) and maximum reaching distances (colored red in Fig. 1A and 1B) at $0^{\circ}$, $45^{\circ}$, and $90^{\circ}$ for the left hand $(0 \mathrm{~L}, 45 \mathrm{~L}$, and $90 \mathrm{~L})$ and at $90^{\circ}$, $135^{\circ}$, and $180^{\circ}$ for the right hand (90R, 135R, and 180R) with the subject in the sitting position. Conventional reaching distances were measured with each hand level with the shoulders, as shown in Fig. 1C. The maximum reaching distance was measured with the hands at the same level but with the subject reaching as far possible, as shown in Fig. 1B. Participants were then instructed to catch a virtual square box at the thoracic level (Fig. 1C). The box fell from a $3 \mathrm{~m}$ height at pre-determined horizontal distances tailor-made for each participant. The horizontal distances were classified into two categories, namely long and middle, and were calculated using the following formulas: $0.9 *$ maximum reaching distance and $0.9 *$ (conventional + maximum reaching distances) $/ 2$, respectively. If the participant failed to catch a virtual square box, for safety reasons, the box disappeared at a height of $20 \mathrm{~cm}$ above the floor. The censoring area of the square box was $4 \mathrm{~cm}$ per side for measurement accuracy, and this was indicated by an outlined pale box with $20 \mathrm{~cm}$ on a side for visibility. The censoring area of the handheld controllers had a $2 \mathrm{~cm}$ spherical diameter. The purpose of the reaching tasks was to stimulate body trunk balance, and to train participants to balance for stable walking. During the 

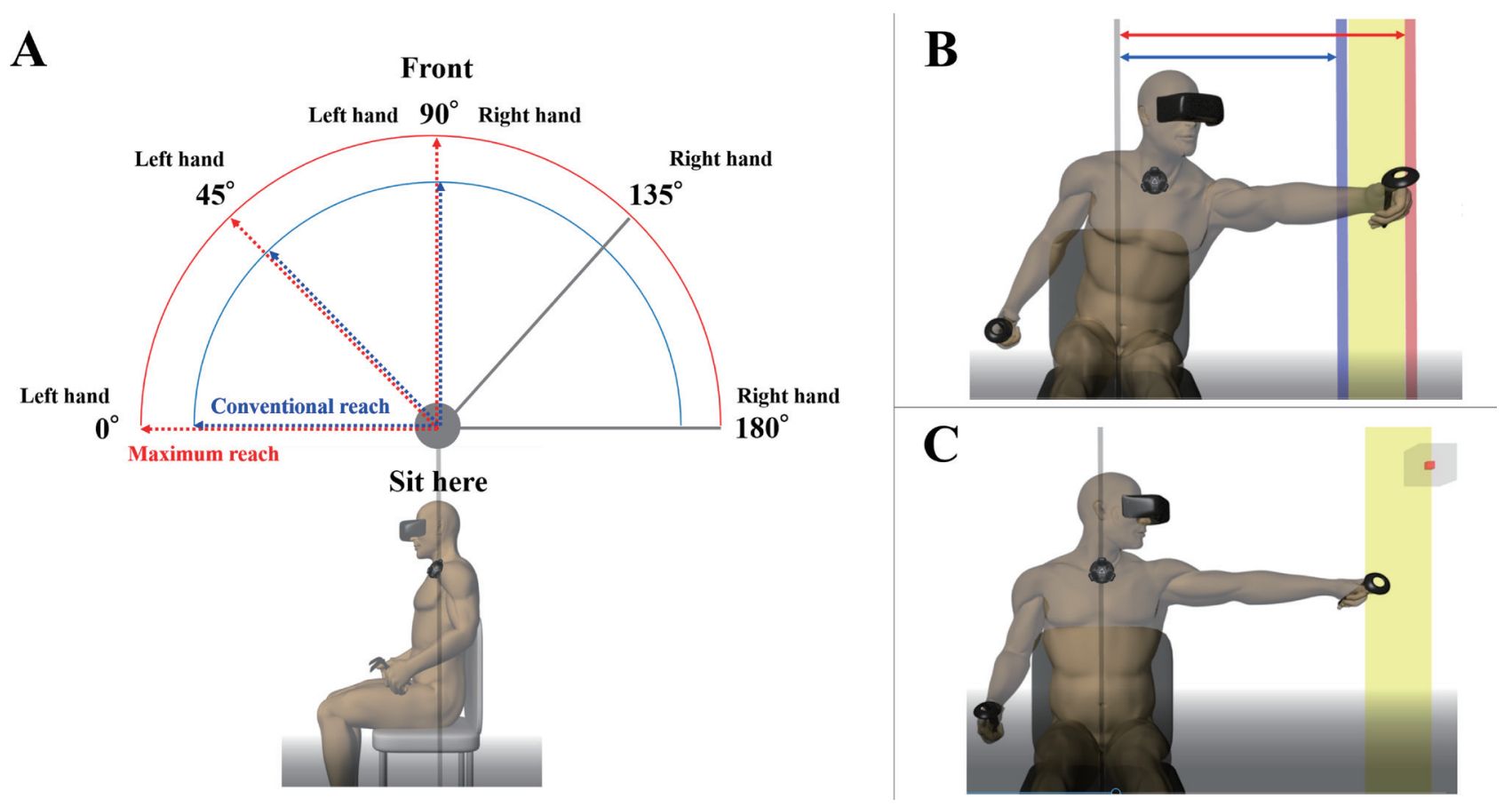

Fig. 1. Concepts of the mediVR01 system. After assessment of the subject's body trunk balance (A and B), a tailor-made rehabilitation training program was provided with the subject in the sitting position $(C)$. The purpose of reaching with the hands was to stimulate body trunk balance and to train participants to balance. With VR and three-dimensional tracking technologies, the stimulation inputs for body trunk balance could be quantitatively provided by setting the reaching distances. Cognitive function was also stimulated to provide dual-task training in a uniform VR environment.

program, the direction and horizontal distance of the box in the following task was indicated by the HMD. We expected that the provision of this information would cause the participants to internalize the nature of the next task and would therefore result in a higher success rate. By repeatedly allowing the participants to think about the timing and distance of the next target, cognitive function was simultaneously stimulated to provide dual-task training. ${ }^{12-14)}$ We measured the horizontal distances for each handheld controller and the central tracker during each training exercise to evaluate the achievement rate for each task. We thereby provided participants with quantitative information about trunk control and quantitatively evaluated their achievement for each task during the tailor-made, dual-task, rehabilitation training program.

The four parameters of the rehabilitation programs in the present study were as follows: (1) distance (middle or long), (2) direction (0L, 45L, 90L, 90R, 135R, or 180R), (3) falling speed of the square box (55 or $75 \mathrm{~cm} / \mathrm{s}$ ), and (4) the interval between tasks $(1,3$, or $5 \mathrm{~s})$. To provide another parameter for cognitive function stimulation, it is possible to change the size of the center or outline of the falling box or the sensing sphere. However, these sizes were fixed in the present study. Participants first underwent two practice rehabilitation programs to familiarize themselves with VR rehabilitation, followed by two exercise rehabilitation programs (normal and hard). If participants could understand how to use the system after the first practice rehabilitation program, the second practice program could be skipped. Detailed protocols are shown in Table 1. Elderly participants ( $\geq 65$ years old) required approximately $15 \mathrm{~min}$ to complete all the programs, whereas young participants took $10 \mathrm{~min}$. If a falling square box was caught by the participant, the task was recorded as a success. For each subject, we evaluated the total success rates of Exercise 1 and Exercise 2 as defined in Table 1. Provision of the rehabilitation programs was either personalized or in groups. In group sessions, three or more participants came together, with one undergoing the rehabilitation program while the other participants observed. To prevent subjects falling from the chair, safety management was provided by a caregiver positioned by the participant during the rehabilitation session. 
Table 1. Practice and exercise rehabilitation programs carried out using the mediVR01 system

\begin{tabular}{|c|c|c|c|c|}
\hline Program & Falling speed & Interval & Tasks & Protocol \\
\hline Practice 1 & $\begin{array}{l}\text { Elderly } 55 \mathrm{~cm} / \mathrm{s} \\
\text { Young } 75 \mathrm{~cm} / \mathrm{s}\end{array}$ & $5 \mathrm{~s}$ & 24 & $\begin{array}{l}\text { Middle distance } \\
\text { 0L-0L-45L-45L-90L-90L-180R-180R-135R-135R-90R-90R } \\
\text { Long distance } \\
\text { 0L-0L-45L-45L-90L-90L-180R-180R-135R-135R-90R-90R }\end{array}$ \\
\hline Practice 2 & $\begin{array}{l}\text { Elderly } 55 \mathrm{~cm} / \mathrm{s} \\
\text { Young } 75 \mathrm{~cm} / \mathrm{s}\end{array}$ & $3 \mathrm{~s}$ & 24 & $\begin{array}{l}\text { Middle distance } \\
\text { 0L-0L-45L-45L-90L-90L-180R-180R-135R-135R-90R-90R } \\
\text { Long distance } \\
\text { 0L-0L-45L-45L-90L-90L-180R-180R-135R-135R-90R-90R }\end{array}$ \\
\hline $\begin{array}{l}\text { Exercise } 1 \\
\text { (normal) }\end{array}$ & $\begin{array}{l}\text { Elderly } 55 \mathrm{~cm} / \mathrm{s} \\
\text { Young } 75 \mathrm{~cm} / \mathrm{s}\end{array}$ & $3 \mathrm{~s}$ & 24 & $\begin{array}{l}\text { Long distance } \\
\text { 90R-0L-135R-45L-180R-90L-135R-0L-90R-45L-135R-90L- } \\
\text { 180R-0L-90R-45L-180R-90L-135R-0L-90R-45L-180R-90L }\end{array}$ \\
\hline $\begin{array}{l}\text { Exercise } 2 \\
\text { (hard) }\end{array}$ & $\begin{array}{l}\text { Elderly } 55 \mathrm{~cm} / \mathrm{s} \\
\text { Young } 75 \mathrm{~cm} / \mathrm{s}\end{array}$ & $1 \mathrm{~s}$ & 24 & $\begin{array}{l}\text { Long distance } \\
\text { 90R-0L-135R-45L-90R-0L-135R-90L-180R-45L-180R-90L- } \\
\text { 180R-0L-135R-90L-135R-45L-90R-0L-90R-45L-180R-90L }\end{array}$ \\
\hline
\end{tabular}

Each program had four parameters: (1) horizontal distance (middle or long), (2) direction (0L, 45L, 90L, 90R, 135R, or 180R), (3) falling speed of the square box (55 or $75 \mathrm{~cm} / \mathrm{s})$, and (4) the interval between tasks (1, 3, or 5 s). Participants first underwent two practice rehabilitation programs to familiarize themselves with VR rehabilitation. This was followed by two exercise rehabilitation programs (normal and hard). $0 \mathrm{~L}, 45 \mathrm{~L}$, and $90 \mathrm{~L}$ are orientations of $0^{\circ}, 45^{\circ}$, and $90^{\circ}$ for the left hand, whereas $90 \mathrm{R}, 135 \mathrm{R}$, and $180 \mathrm{R}$ are orientations of $90^{\circ}, 135^{\circ}$, and $180^{\circ}$ for the right hand.

\section{Endpoints and Statistical Analysis}

The primary endpoint was the safety of mediVR01, which was evaluated based on the number of simulator sickness questionnaire (SSQ) symptoms. ${ }^{18)}$ SSQ was administered before, immediately after, and 3 days after the VR rehabilitation programs. SSQ consisted of 16 parameters that were each evaluated in four categories: none, slight, moderate, and severe. ${ }^{18)}$ The secondary endpoints were adverse events (such as falls from the chair, any injuries, or unexpected discontinuation of the rehabilitation program) and the feasibility of mediVR01, which was evaluated using a five-point Likert scale questionnaire on satisfaction and sense of achievement. These secondary endpoints may reflect the overall severity of SSQ symptoms and describe the degree of safety. Continuous variables were summarized using medians and interquartile ranges (IQRs, quartiles 1 to 3 ), whereas categorical variables were summarized using counts and percentages. The statistical significance of the pre- and postprocedural number of SSQ symptoms in each participant was evaluated using the Wilcoxon signed-rank test considering parity. We defined elderly participants as those aged $\geq 65$ years. The Pinteraction between the elderly and young participants was also evaluated using linear regression analysis by including the postprocedural number of symptoms as the objective variable and preprocedural number of symptoms as the explanatory variable, with the elderly participants as the interaction term. Differences in the prevalence of second- ary endpoints between the elderly and young participants or types of attendance were evaluated using the chi-square test. All statistical analyses were performed using Microsoft R Open Software (version 3.3.2, Microsoft Corporation, Redmond, WA, USA).

\section{RESULTS}

Participant characteristics are shown in Table 2. The median age was 68 years (IQR 57-73 years), with $67.7 \%$ being elderly and $54.8 \%$ being male. None had used a VR device before the study, and $32.3 \%$ wore eyeglasses. Eleven (35.5\%) participants had experienced car sickness in their daily life, $9(29.0 \%)$ played video or smartphone games, and $20(64.5 \%)$ underwent the rehabilitation program in groups.

The total success rate for the normal exercise rehabilitation program defined as Exercise 1 in Table 1 was 95.8\% $(85.4 \%-100.0 \%)$. There was a statistically significant difference between the elderly and young participants $(87.5 \%$ [75.0\%-95.8\%] vs. $100.0 \%$ [96.9\%-100.0\%]; $\mathrm{P}=0.005)$. In contrast, the total success rate for the hard exercise rehabilitation program, defined as Exercise 2 in Table 1, was $45.8 \%(33.3 \%-58.3 \%)$. There was no statistically significant difference between the elderly and young participants $(45.8 \%$ $[33.3 \%-58.3 \%]$ vs. $54.2 \%$ [39.6\%-57.3\%]; $\mathrm{P}=0.497)$.

With respect to the primary endpoint (Table 3), the postprocedural number of SSQ symptoms, especially the 
75th percentile value, significantly increased from $0(0-0)$ to $0(0-1.5)(\mathrm{P}=0.009)$. Furthermore, there was a significant difference in the postprocedural number of SSQ symptoms between young participants (from $0[0-0]$ to $1[0-2.75]$ ) and elderly participants (from $0[0-0]$ to $0[0-0]$ ) (interaction effect, $\mathrm{P}<0.001)$. All SSQ symptoms were reported to be slight, except for those in the youngest participant (29 years old), who had preprocedural symptoms of slight fatigue and had slight eyestrain and who, after rehabilitation, had moderate eyestrain, moderate difficulty in focusing, moderate sweating, moderate blurred vision, and moderate stomach awareness. The most frequent symptom was sweating (22.6\%), followed by fatigue (19.4\%), eyestrain (12.9\%), difficulty in focusing (12.9\%), and blurred vision (12.9\%). However, subsequently, all SSQ symptoms improved, and no participants showed any SSQ symptom 3 days after the rehabilitation program.

With respect to the secondary endpoints, no falls from the chair or injuries occurred. One 72-year-old participant unexpectedly discontinued the rehabilitation program because he unintentionally pushed the emergency stop button, with which the device was equipped for safety reasons. He then redid the normal exercise rehabilitation program after a computer reboot; the total procedural time was extended to $20 \mathrm{~min}$ (i.e., an additional $5 \mathrm{~min}$ ). Consequently, all participants completed the rehabilitation programs without any adverse events. Figure 2 shows the results of the five-point Likert scale questionnaire survey on satisfaction and sense of achievement. All participants considered the VR rehabilitation programs to be enjoyable, and the majority (93.5\%) reported a sense of achievement. However, some participants complained about the short duration of the rehabilitation programs. Interestingly, group attendance was associated with higher satisfaction levels $(\mathrm{P}=0.049)$.

\section{DISCUSSION}

In the present study, we evaluated the safety and feasibility of a new off-label medical device intended to improve body trunk balance. The device provided participants with a standardized, tailor-made, dual-task, exercise rehabilitation program with a level of gamification. The main findings were as follows: (1) The number of SSQ symptoms significantly increased immediately after the rehabilitation program, and this was mainly attributable to increased symptoms in young participants. (2) All participants successfully completed the rehabilitation programs without any adverse events such as falls or injuries. (3) All participants considered the VR rehabilitation programs to be enjoyable, despite their lack of previous VR experience, and most participants reported a sense of achievement. (4) Group attendance was associated with higher satisfaction levels.

\section{VR-induced Sickness Assessed by SSQ}

To provide participants with quantitative instructions and to quantitatively evaluate achievements, we employed VR and three-dimensional tracking technologies. The most important safety problem of VR in the clinical setting is VRinduced sickness, which is believed to occur as a result of discrepancies among sensory inputs, such as those between visual and vestibular senses, known as sensory conflict. ${ }^{19)}$ To minimize VR-induced sickness, we selected HTC Vive because its HMD can operate at $>90 \mathrm{fps}$, which may be sufficient to avoid frame delay and visual lag during the rehabilitation program. ${ }^{19)}$ In our rehabilitation program, we fixed the landscape to avoid sensory conflict and stimulated the cognitive function using the following four parameters of the falling box: horizontal distance, direction, falling speed, and interval between tasks. Even with these efforts to minimize VR-induced sickness, the number of SSQ symptoms significantly increased immediately after the rehabilitation program, and this was mainly attributable to an increase in symptoms in young participants. However, we believe that the two most frequent SSQ symptoms, namely sweating and fatigue, are natural responses to exercise rehabilitation and do not require caution in our view. Therefore, one of the important lessons from our study with respect to VR-induced sickness is that we need to exercise caution during rehabilitation, especially when providing programs for young participants. The increase in SSQ symptoms in younger participants may partly be explained by their tendency to become enthusiastic to successfully catch the square boxes.

We intentionally provided an exercise rehabilitation program within a field greater than the $110^{\circ}$ field of view of the HTC Vive HMD because restricting the body trunk balance exercises within $110^{\circ}$ is not realistic in the clinical setting. For example, several tasks such as $0 \mathrm{~L}-135 \mathrm{R}$ or $180 \mathrm{R}-0 \mathrm{~L}$ need body trunk balance at $135^{\circ}$ or $180^{\circ}$, respectively. It is possible that this type of exercise rehabilitation program may have elicited sensory conflict and resulted in increased SSQ symptoms in this study. Increasing the field of view of the VR HMD could potentially result in a reduction in VRinduced sickness in the future.

\section{Other Safety Problems}

To safely operate a standardized rehabilitation program 
Table 2. Participant characteristics

\begin{tabular}{lc}
\hline Parameter & $\mathrm{n}=31$ \\
\hline Age, years & $68(57-73)$ \\
Elderly ( $\geq 65$ years old) & $21(67.7)$ \\
Male & $17(54.8)$ \\
Height, cm & $160(155-166)$ \\
Weight, kg & $61.0(50.8-72.5)$ \\
Previous VR experience & $0(0.0)$ \\
Wearing eyeglasses & $10(32.3)$ \\
Vision problem (questionnaire) & \\
Myopia & $12(38.7)$ \\
Hyperopia & $3(9.7)$ \\
Astigmatism & $8(25.8)$ \\
Presbyopia & $12(38.7)$ \\
Car sickness & \\
Often & $1(3.2)$ \\
Sometimes & $4(12.9)$ \\
Rarely & $6(19.4)$ \\
Never & $20(64.5)$ \\
Playing video/smartphone games & \\
Often & $0(0.0)$ \\
Sometimes & $4(12.9)$ \\
Rarely & $5(16.1)$ \\
Never & $22(71.0)$ \\
Type of attendance & \\
Personalized & $11(35.5)$ \\
Group ( $\geq$ three participants) & $20(64.5)$ \\
\hline Cont &
\end{tabular}

Continuous variables are given as medians and interquartile ranges, whereas categorical variables are summarized using counts and percentages.

VR, virtual reality.

without human medical resources, our program was executed with the participants sitting on an upright chair, rather than standing. The rationale for this was the fact that two-thirds of the total body weight is centered in the upper body, which results in inherent balance instability in humans. ${ }^{20)}$ Consequently, we speculated that upper body balance training, even in a sitting position, may exhibit reasonable degrees of both efficacy and safety, although efficacy was not evaluated in this study. All participants successfully completed the rehabilitation programs without significant adverse events such as fall or injuries. We believe that the disappearance of the square boxes at a height of $20 \mathrm{~cm}$ also contributed to safety.

To proactively evaluate the safety of our exercise rehabilitation program, participants finished with a hard exercise rehabilitation program (Table 1) that was expected to be very difficult to deal with. As anticipated, the overall success rate for the hard exercise rehabilitation program, defined as Exercise 2 in Table 1, was less than 50\%, and there was no statistical difference between the elderly and young participants. This finding suggests that our exercise rehabilitation program was intentionally interruptible and did not result in adverse events such as a fall.

\section{Feasibility Evaluation}

Contrary to our expectations, all participants, including the elderly, found the VR rehabilitation programs enjoyable, despite their lack of previous VR experience. Compared with the young participants, the elderly participants tended to consider the VR rehabilitation programs as very enjoyable, although the difference was not statistically significant. The reason for this may have been that our main targets were the 
Table 3. Results of the simulator sickness questionnaire survey

\begin{tabular}{|c|c|c|c|}
\hline & $\begin{array}{c}\text { Before VR rehabilitation } \\
\text { programs }\end{array}$ & $\begin{array}{l}\text { Immediately after VR } \\
\text { rehabilitation programs }\end{array}$ & $\begin{array}{l}\text { Three days after VR } \\
\text { rehabilitation programs }\end{array}$ \\
\hline No. of symptoms in each participant & $0(0-0)$ & $0(0-1.5)$ & $0(0-0)$ \\
\hline Elderly & $0(0-0)$ & $0(0-0)$ & $0(0-0)$ \\
\hline Young & $0(0-0)$ & $1(0-2.75)$ & $0(0-0)$ \\
\hline \multicolumn{4}{|l|}{ Detailed components } \\
\hline 1. General discomfort & $0(0.0)$ & $2(6.5)$ & $0(0.0)$ \\
\hline 2. Fatigue & $1(3.2)$ & $6(19.4)$ & $0(0.0)$ \\
\hline 3. Headache & $0(0.0)$ & $0(0.0)$ & $0(0.0)$ \\
\hline 4. Eyestrain & $1(3.2)$ & $4(12.9)$ & $0(0.0)$ \\
\hline 5. Difficulty in focusing & $1(3.2)$ & $4(12.9)$ & $0(0.0)$ \\
\hline 6. Increased salivation & $0(0.0)$ & $1(3.2)$ & $0(0.0)$ \\
\hline 7. Sweating & $0(0.0)$ & $7(22.6)$ & $0(0.0)$ \\
\hline 8. Nausea & $0(0.0)$ & $0(0.0)$ & $0(0.0)$ \\
\hline 9. Difficulty in concentrating & $0(0.0)$ & $0(0.0)$ & $0(0.0)$ \\
\hline 10. Fullness in the head & $0(0.0)$ & $1(3.2)$ & $0(0.0)$ \\
\hline 11. Blurred vision & $2(6.5)$ & 4 (12.9) & $0(0.0)$ \\
\hline 12. Dizziness with eyes open & $0(0.0)$ & $3(9.7)$ & $0(0.0)$ \\
\hline 13. Dizziness with eyes closed & $0(0.0)$ & $1(3.2)$ & $0(0.0)$ \\
\hline 14. Vertigo & $0(0.0)$ & $1(3.2)$ & $0(0.0)$ \\
\hline 15. Stomach awareness & $0(0.0)$ & $1(3.2)$ & $0(0.0)$ \\
\hline 16. Burping & $0(0.0)$ & $0(0.0)$ & $0(0.0)$ \\
\hline
\end{tabular}

Continuous variables are given as medians and interquartile ranges, whereas categorical variables are summarized using counts and percentages.

All symptoms were reported to be "slight," except for those in a 29 -year-old man with preprocedural symptoms of slight fatigue and slight eyestrain who had moderate eyestrain, moderate difficulty in focusing, moderate sweating, moderate blurred vision, and moderate stomach awareness immediately after rehabilitation.

elderly participants, and the normal exercise rehabilitation program was likely too easy or left much to be desired for the young participants, as suggested by the very high success rate. Furthermore, we showed that group attendance was associated with higher satisfaction. It appears that the concept of mutual-help group participation, applied as a treatment strategy for alcohol or drug abuse, may also be applicable to the field of rehabilitation. ${ }^{21,22)}$

\section{Clinical Implication}

Recently, gamification has been widely introduced into many medical disciplines, especially in the digital healthcare fields, including e-learning and self-administered physical training programs. ${ }^{16,17)}$ Moreover, the remarkable success of the augmented reality game Pokémon GO (Niantic, Inc., San Francisco, CA, USA), which might inadvertently contribute to public or psychiatric health, shows the potential for the new healthcare approach of entertainment with a hidden healthcare agenda. ${ }^{23-25)}$

\section{Study Limitations}

This study has several limitations that should be considered during data interpretation. First, the number of participants is low. Second, a significant selection bias exists because enrolments were made based on voluntary participation. Lastly, we did not evaluate the efficacy of the mediVR01 system in this study. Some physicians have suggested that the use of two-dimensional programs, such as Nintendo Wii Fit $^{\mathrm{TM}}$ (Nintendo, Kyoto, Japan), that encourage physical activities or exercise, cannot with certainty lead to an intended therapeutic effect. The reason they give is the inability of such programs to provide accurate instructions and quantitative assessments, despite such programs exhibiting a certain level of efficacy, especially on Berg balance scores and the timed-up-and-go test, and despite their very high levels of safety and feasibility (similar to those found in the current study). ${ }^{17,26,27)}$ However, our novel quantitative tailor-made rehabilitation approach has the potential to resolve this problem by providing accurate instructions and quantitative 


\section{Enjoyment}

\section{A. Total Population}

$0.0 \quad 0.0$

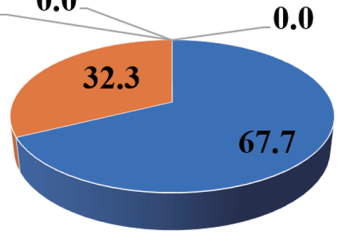

F. Total Population

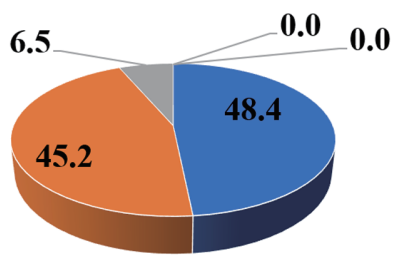

\section{Sense of Achievement}

B. Elderly Participants

C. Young Participants

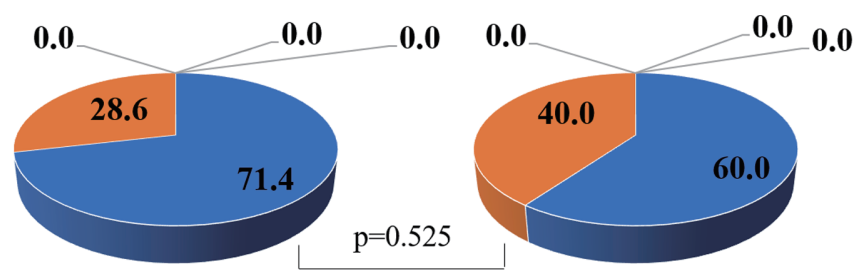

D. Personalized Attendance

E. Group Attendance

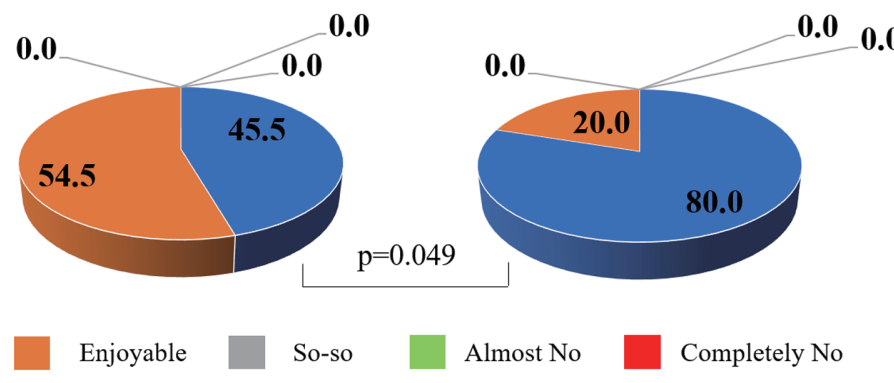

\section{G. Elderly Participants}

\section{H. Young Participants}

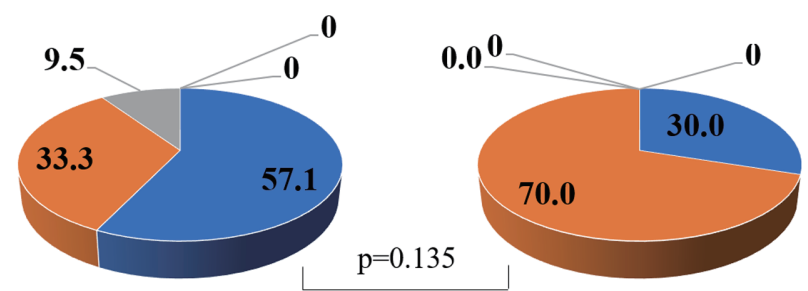

I. Personalized Attendance

\section{J. Group Attendance}

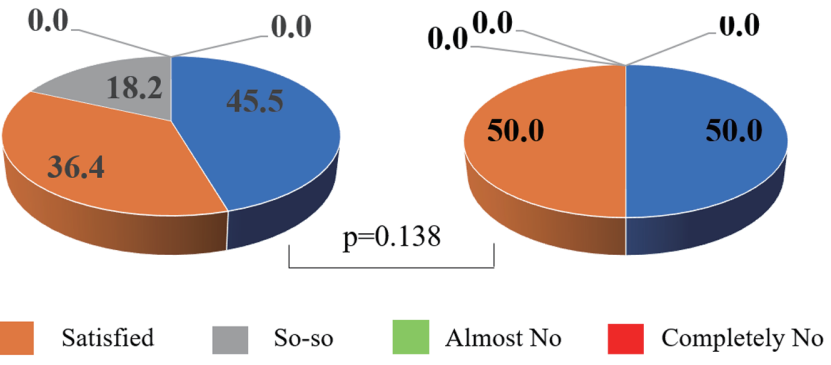

Fig. 2. Satisfaction and sense of achievement. Results of a 5-point Likert scale questionnaire on satisfaction (A-E) and sense of achievement (F-J).

assessments. The efficacy and effect of our system on the recovery of walking ability, the alleviation of human resource problems, and cost reduction are pertinent issues for future research.

\section{CONCLUSIONS}

Our tailor-made, dual-task rehabilitation training program for body trunk balance using VR and three-dimensional tracking technologies was safe and feasible, even for elderly participants. 


\section{ACKNOWLEDGEMENT}

This research received no specific grant from any funding agency in the public, commercial, or not-for-profit sectors.

\section{CONTRIBUTORS}

Masahiko Hara, Tetsuhisa Kitamura, Yuichiro Murakawa, Kyosuke Shimba, Shimpei Yamaguchi, and Masatake Tamaki (1) provided substantial contributions to the conception or design of the study or the acquisition, analysis, or interpretation of data; (2) drafted the paper or revised it critically for important intellectual content; (3) provided final approval of the version to be published; and (4) agreed to be accountable for all aspects of the work in ensuring that questions related to the accuracy or integrity of any part of the work are appropriately investigated and resolved.

\section{CONFLICT OF INTEREST}

Masahiko Hara, Kyosuke Shimba, Shimpei Yamaguchi, and Masatake Tamaki are stock holders of mediVR, Inc., a company with unlisted stock and ongoing international Patent Cooperation Treaty applications that holds a patent on dual-task training and updating the target value of rehabilitation based on achievement rates (patent no. 6200615 in Japan). However, this research received no specific grant from any funding agency in the public, commercial, or notfor-profit sectors.

\section{REFERENCES}

1. Gill TM, Allore HG, Hardy SE, Guo Z: The dynamic nature of mobility disability in older persons. J Am Geriatr Soc 2006;54:248-254. PMID:16460375, DOI:10.1111/j.1532-5415.2005.00586.x

2. Mahlknecht P, Kiechl S, Bloem BR, Willeit J, Scherfler C, Gasperi A, Rungger G, Poewe W, Seppi K: Prevalence and burden of gait disorders in elderly men and women aged 60-97 years: a population-based study. PLoS One 2013;8:e69627. PMID:23894511, DOI:10.1371/journal.pone.0069627

3. Stolze H, Klebe S, Baecker C, Zechlin C, Friege L, Pohle S, Deuschl G: Prevalence of gait disorders in hospitalized neurological patients. Mov Disord 2005;20:89-94. PMID:15390043, DOI:10.1002/mds.20266

4. Gobbens RJ, van Assen MA, Luijkx KG, Schols JM: The predictive validity of the Tilburg Frailty Indicator: disability, health care utilization, and quality of life in a population at risk. Gerontologist 2012;52:619-631. PMID:22217462, DOI:10.1093/geront/gnr135

5. Tomlinson CL, Patel S, Meek C, Herd CP, Clarke CE, Stowe R, Shah L, Sackley C, Deane KH, Wheatley $\mathrm{K}$, Ives N: Physiotherapy intervention in Parkinson's disease: systematic review and meta-analysis. BMJ 2012;345:e5004. PMID:22867913, DOI:10.1136/bmj. e5004

6. Gill TM, Gahbauer EA, Han L, Allore HG: Functional trajectories in older persons admitted to a nursing home with disability after an acute hospitalization. J Am Geriatr Soc 2009;57:195-201. PMID:19170778, DOI:10.1111/j.1532-5415.2008.02107.x

7. Murray CJ, Vos T, Lozano R, Naghavi M, Flaxman AD, Michaud C, Ezzati M, Shibuya K, Salomon JA, Abdalla S, Aboyans V, Abraham J, Ackerman I, Aggarwal R, Ahn SY, Ali MK, AlMazroa MA, Alvarado M, Anderson HR, Anderson LM, Andrews KG, Atkinson C, Baddour LM, Bahalim AN, Barker-Collo S, Barrero LH, Bartels DH, Basáñez MG, Baxter A, Bell ML, Benjamin EJ, Bennett D, Bernabé E, Bhalla $\mathrm{K}$, Bhandari B, Bikbov B, Abdulhak AB, Birbeck G, Black JA, Blencowe H, Blore JD, Blyth F, Bolliger I, Bonaventure A, Boufous S, Bourne R, Boussinesq M, Braithwaite T, Brayne C, Bridgett L, Brooker S, Brooks P, Brugha TS, Bryan-Hancock C, Bucello C, Buchbinder R, Buckle G, Budke CM, Burch M, Burney P, Burstein R, Calabria B, Campbell B, Canter CE, Carabin H, Carapetis J, Carmona L, Cella C, Charlson F, Chen H, Cheng AT, Chou D, Chugh SS, Coffeng LE, Colan SD, Colquhoun S, Colson KE, Condon J, Connor MD, Cooper LT, Corriere M, Cortinovis M, de Vaccaro KC, Couser W, Cowie BC, Criqui MH, Cross M, Dabhadkar KC, Dahiya M, Dahodwala N, DamsereDerry J, Danaei G, Davis A, Leo DD, Degenhardt L, Dellavalle R, Delossantos A, Denenberg J, Derrett S, Des Jarlais DC, Dharmaratne SD, Dherani M, DiazTorne C, Dolk H, Dorsey ER, Driscoll T, Duber H, Ebel B, Edmond K, Elbaz A, Ali SE, Erskine H, Erwin PJ, Espindola P, Ewoigbokhan SE, Farzadfar F, Feigin V, Felson DT, Ferrari A, Ferri CP, Fèvre EM, Finucane MM, Flaxman S, Flood L, Foreman K, Forouzanfar MH, Fowkes FG, Fransen M, Freeman MK, Gabbe BJ, Gabriel SE, Gakidou E, Ganatra HA, Garcia B, Gaspari F, Gillum RF, Gmel G, Gonzalez-Medina D, Gosselin R, Grainger R, Grant B, Groeger J, Guillemin F, Gunnell D, Gupta R, Haagsma J, Hagan H, Halasa YA, 
Hall W, Haring D, Haro JM, Harrison JE, Havmoeller R, Hay RJ, Higashi H, Hill C, Hoen B, Hoffman H, Hotez PJ, Hoy D, Huang JJ, Ibeanusi SE, Jacobsen KH, James SL, Jarvis D, Jasrasaria R, Jayaraman S, Johns N, Jonas JB, Karthikeyan G, Kassebaum N, Kawakami N, Keren A, Khoo JP, King CH, Knowlton LM, Kobusingye O, Koranteng A, Krishnamurthi R, Laden F, Lalloo R, Laslett LL, Lathlean T, Leasher JL, Lee YY, Leigh J, Levinson D, Lim SS, Limb E, Lin JK, Lipnick M, Lipshultz SE, Liu W, Loane M, Ohno SL, Lyons R, Mabweijano J, MacIntyre MF, Malekzadeh R, Mallinger L, Manivannan S, Marcenes W, March L, Margolis DJ, Marks GB, Marks R, Matsumori A, Matzopoulos R, Mayosi BM, McAnulty JH, McDermott MM, McGill N, McGrath J, Medina-Mora ME, Meltzer M, Memish ZA, Mensah GA, Merriman TR, Meyer AC, Miglioli V, Miller M, Miller TR, Mitchell PB, Mock C, Mocumbi AO, Moffitt TE, Mokdad AA, Monasta L, Montico M, Moradi-Lakeh M, Moran A, Morawska L, Mori R, Murdoch ME, Mwaniki MK, Naidoo K, Nair MN, Naldi L, Narayan KM, Nelson PK, Nelson RG, Nevitt MC, Newton CR, Nolte S, Norman P, Norman R, O’Donnell M, O'Hanlon S, Olives C, Omer SB, Ortblad K, Osborne R, Ozgediz D, Page A, Pahari B, Pandian JD, Rivero AP, Patten SB, Pearce N, Padilla RP, Perez-Ruiz F, Perico N, Pesudovs K, Phillips D, Phillips MR, Pierce K, Pion S, Polanczyk GV, Polinder S, Pope CA III, Popova S, Porrini E, Pourmalek F, Prince M, Pullan RL, Ramaiah KD, Ranganathan D, Razavi H, Regan M, Rehm JT, Rein DB, Remuzzi G, Richardson K, Rivara FP, Roberts T, Robinson C, De Leòn FR, Ronfani L, Room R, Rosenfeld LC, Rushton L, Sacco RL, Saha S, Sampson U, Sanchez-Riera L, Sanman E, Schwebel DC, Scott JG, Segui-Gomez M, Shahraz S, Shepard DS, Shin H, Shivakoti R, Silberberg D, Singh D, Singh GM, Singh JA, Singleton J, Sleet DA, Sliwa K, Smith E, Smith JL, Stapelberg NJ, Steer A, Steiner T, Stolk WA, Stovner LJ, Sudfeld C, Syed S, Tamburlini G, Tavakkoli M, Taylor HR, Taylor JA, Taylor WJ, Thomas B, Thomson WM, Thurston GD, Tleyjeh IM, Tonelli M, Towbin JA, Truelsen T, Tsilimbaris MK, Ubeda C, Undurraga EA, van der Werf MJ, van Os J, Vavilala MS, Venketasubramanian $\mathrm{N}$, Wang $\mathrm{M}$, Wang $\mathrm{W}$, Watt $\mathrm{K}$, Weatherall DJ, Weinstock MA, Weintraub R, Weisskopf MG, Weissman MM, White RA, Whiteford H, Wiebe N, Wiersma ST, Wilkinson JD, Williams HC, Williams SR, Witt E, Wolfe F, Woolf AD, Wulf S, Yeh PH, Zaidi AK, Zheng
ZJ, Zonies D, Lopez AD: Disability-adjusted life years (DALYs) for 291 diseases and injuries in 21 regions, 1990-2010: a systematic analysis for the Global Burden of Disease Study 2010. Lancet 2012;380:2197-2223. PMID:23245608, DOI:10.1016/S0140-6736(12)61689-4

8. Gilmore B, MacLachlan M, McVeigh J, McClean C, Carr S, Duttine A, Mannan H, McAuliffe E, Mji G, Eide AH, Hem KG, Gupta N: A study of human resource competencies required to implement community rehabilitation in less resourced settings. Hum Resour Health 2017;15:70. PMID:28938909, DOI:10.1186/ s12960-017-0240-1

9. Chan L, Beaver S, MacLehose RF, Jha A, Maciejewski M, Doctor JN: Disability and health care costs in the Medicare population. Arch Phys Med Rehabil 2002;83:1196-1201. PMID:12235597, DOI:10.1053/ apmr.2002.34811

10. Gordon NF, Gulanick M, Costa F, Fletcher G, Franklin BA, Roth EJ, Shephard T, American Heart Association Council on Clinical Cardiology, Subcommittee on Exercise, Cardiac Rehabilitation, and Prevention; the Council on Cardiovascular Nursing; the Council on Nutrition, Physical Activity, and Metabolism; and the Stroke Council: Physical activity and exercise recommendations for stroke survivors. Stroke 2004;35:1230-1240. PMID:15105522, DOI:10.1161/01. STR.0000127303.19261.19

11. Podsiadlo D, Richardson S: The timed "Up \& Go": a test of basic functional mobility for frail elderly persons. J Am Geriatr Soc 1991;39:142-148. PMID:1991946, DOI:10.1111/j.1532-5415.1991.tb01616.x

12. Yamada M, Tanaka B, Nagai K, Aoyama T, Ichihashi $\mathrm{N}$ : Trail-walking exercise and fall risk factors in community-dwelling older adults: preliminary results of a randomized controlled trial. J Am Geriatr Soc 2010;58:1946-1951. PMID:20831723, DOI:10.1111/ j.1532-5415.2010.03059.x

13. Trombetti A, Hars M, Herrmann FR, Kressig RW, Ferrari S, Rizzoli R: Effect of music-based multitask training on gait, balance, and fall risk in elderly people: a randomized controlled trial. Arch Intern Med 2011;171:525-533. PMID:21098340, DOI:10.1001/ archinternmed.2010.446

14. Mirelman A, Rochester L, Maidan I, Del Din S, Alcock L, Nieuwhof F, Rikkert MO, Bloem BR, Pelosin E, Avanzino L, Abbruzzese G, Dockx K, Bekkers E, Giladi N, Nieuwboer A, Hausdorff JM: Addition of a non-immersive virtual reality component to 
treadmill training to reduce fall risk in older adults (V-TIME): a randomised controlled trial. Lancet 2016;388:1170-1182. PMID:27524393， DOI:10.1016/ S0140-6736(16)31325-3

15. Dockx K, Bekkers EM, Van den Bergh V, Ginis P, Rochester L, Hausdorff JM, Mirelman A, Nieuwboer A: Virtual reality for rehabilitation in Parkinson's disease. Cochrane Database Syst Rev 2016;12:CD010760. PMID:28000926

16. Sardi L, Idri A, Fernández-Alemán JL: A systematic review of gamification in e-Health. J Biomed Inform 2017;71:31-48. PMID:28536062, DOI:10.1016/j. jbi.2017.05.011

17. Janssen J, Verschuren O, Renger WJ, Ermers J, Ketelaar M, van Ee R: Gamification in physical therapy: more than using games. Pediatr Phys Ther 2017;29:95-99. PMID:27984481, DOI:10.1097/ PEP.0000000000000326

18. Kennedy RS, Lane NE, Berbaum KS, Lilienthal MG: Simulator sickness questionnaire: an enhanced method for quantifying simulator sickness. Int J Aviat Psychol 2009;13:203-220.

19. Nichols S, Patel H: Health and safety implications of virtual reality: a review of empirical evidence. Appl Ergon 2002;33:251-271. PMID:12164509, DOI:10.1016/ S0003-6870(02)00020-0

20. McCollum G, Leen TK: Form and exploration of mechanical stability limits in erect stance. J Mot Behav 1989;21:225-244. PMID:15136262, DOI:10.1080/0022 2895.1989.10735479

21. Tonigan JS, Toscova R, Miller WR: Meta-analysis of the literature on Alcoholics Anonymous: sample and study characteristics moderate findings. J Stud
Alcohol 1996;57:65-72. PMID:8747503, DOI:10.15288/ jsa.1996.57.65

22. Gossop M, Stewart D, Marsden J: Attendance at Narcotics Anonymous and Alcoholics Anonymous meetings, frequency of attendance and substance use outcomes after residential treatment for drug dependence: a 5-year follow-up study. Addiction 2008;103:119-125. PMID:18028521, DOI:10.1111/ j.1360-0443.2007.02050.x

23. Wong MC, Turner P, MacIntyre K, Yee KC: Why augmented reality games offer insights for enhancing public health interventions on obesity-related diseases. Stud Health Technol Inform 2017;241:128-133. PMID:28809195

24. Kamboj AK, Krishna SG, Pokémon GO: Pokémon GO: An innovative smartphone gaming application with health benefits. Prim Care Diabetes 2017;11:397-399. PMID:28457897, DOI:10.1016/j.pcd.2017.03.008

25. Tateno M, Skokauskas N, Kato TA, Teo AR, Guerrero AP: New game software (Pokémon Go) may help youth with severe social withdrawal, hikikomori. Psychiatry Res 2016;246:848-849. PMID:27817905, DOI:10.1016/j.psychres.2016.10.038

26. Tripette J, Murakami H, Ryan KR, Ohta Y, Miyachi M: The contribution of Nintendo Wii Fit series in the field of health: a systematic review and meta-analysis. PeerJ 2017;5:e3600. PMID:28890847, DOI:10.7717/ peerj.3600

27. Agmon M, Perry CK, Phelan E, Demiris G, Nguyen HQ: A pilot study of Wii Fit exergames to improve balance in older adults. J Geriatr Phys Ther 2011;34:161-167. PMID:22124415, DOI:10.1519/JPT.0b013e3182191d98 